NASA Technical Memorandum 106406

$1 N-20$

\title{
Nuclear Electric Propulsion: A "Better, Safer, Cheaper" Transportation System for Human Exploration of Mars
}

John S. Clark, Jeffrey A. George, Leon P. Gefert, Michael P. Doherty, and Robert J. Sefcik

Lewis Research Center

Cleveland, Ohio

Prepared for the 11th Symposium on Space Nuclear Power and Propulsion Systems sponsored by the University of New Mexico Albuquerque, New Mexico, January 9-13, 1994

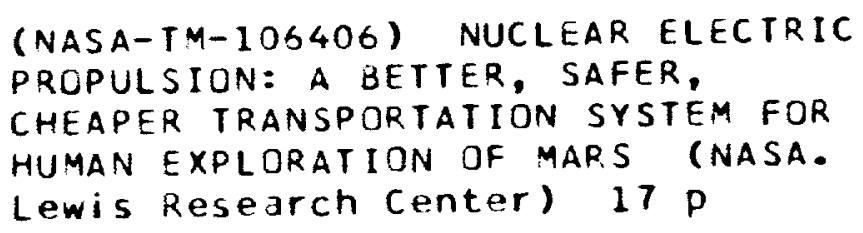




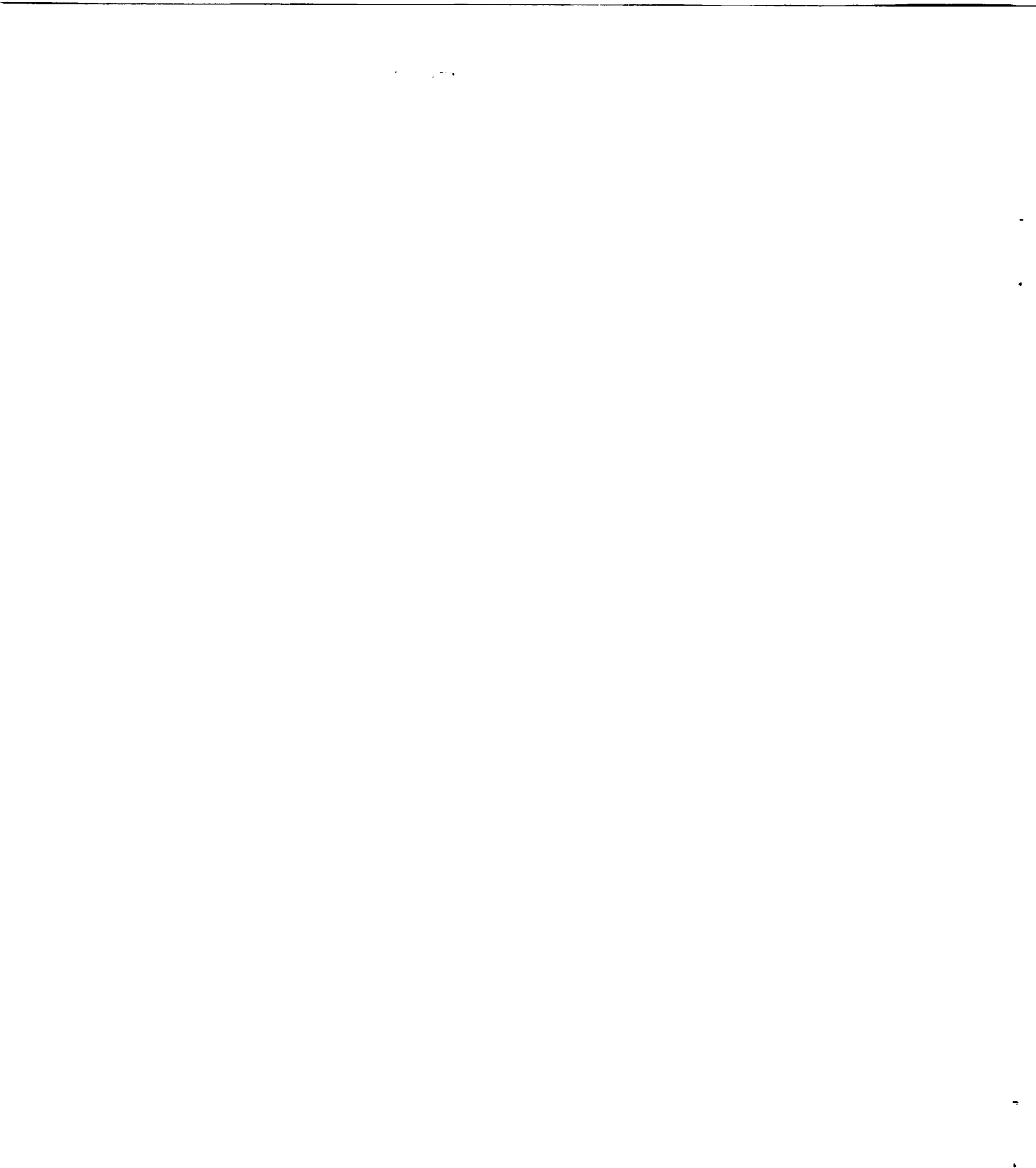




\title{
NUCLEAR ELECTRIC PROPULSION: \\ A "BETTER, SAFER, CHEAPER" TRANSPORTATION SYSTEM FOR HUMAN EXPLORATION OF MARS
}

\author{
John S. Clark, Jeffrey A. George, Leon P. Gefert, Michael P. Doherty, and Robert J. Sefcik \\ NASA Lewis Research Center \\ Cleveland, $\mathrm{OH} 44135$
}

(216) $977-7108$

\begin{abstract}
NASA has completed a preliminary mission and systems study of nuclear electric propulsion (NEP) systems for "split-sprint" human exploration and related robotic cargo missions to Mars. This paper describes the study, the mission architecture selected, the NEP system and technology development needs, proposed development schedules, and estimated development costs. Since current administration policy makers have delayed funding for key technology development activities that could make Mars exploration missions a reality in the near future, NASA will have time to evaluate various alternate mission options, and it appears prudent to ensure that Mars mission plans focus on astronaut and mission safety, while reducing costs to acceptable levels. The split-sprint nuclear electric propulsion system offers trip times comparable to nuclear thermal propulsion (NTP) systems, while providing mission abort opportunities that are not possible with "reference" mission architectures. Thus, NEP systems offer short transit times for the astronauts, reducing the exposure of the crew to intergalactic cosmic radiation. The high specific impulse of the NEP system, which leads to very low propellant requirements, results in significantly lower "initial mass in low earth orbit" (IMLEO). Launch vehicle packaging studies show that the NEP system can be launched, assembled, and deployed, with about one less 240 -metric-ton heavy lift launch vehicle (HLLV) per mission opportunity - a very large cost savings! Technology development cost of the nuclear reactor for an NEP system would be shared with the proposed nuclear surface power systems, since nuclear systems will be required to provide substantial electrical power on the surface of Mars. The NEP development project plan proposed includes evolutionary technology development for nuclear electric propulsion systems that expands upon SP-100 (Space Power - $100 \mathrm{kw}_{\mathrm{e}}$ ) technology that has been developed for lunar and Mars surface nuclear power, and small NEP systems for interplanetary probes. System upgrades are expected to evolve that will result in even shorter trip times, improved payload capabilities, and enhanced safety and reliability. Non-nuclear technology development for the NEP system is estimated to cost about $\$ 721 \mathrm{M}(1993 \$)$. Nuclear technology development costs are not included in the costs in this report, since these costs will be incurred in the nuclear surface power development program. NEP Phase A/B studies are estimated to cost about $\$ 154 \mathrm{M}$. Flight system hardware development (Phase $C / D$ ) is estimated to cost about $\$ 2.8 \mathrm{~B}$, and fabrication of flight hardware is estimated to be about $\$ 7.8 \mathrm{~B}$ for four mission opportunities in 2009, 2011, 2014, and 2016.
\end{abstract}

\section{INTRODUCTION}

Nuclear propulsion has been identified as a critical technology for future space exploration missions (Cohen, 1989). Gilland (1991a, 1991b, and 1992) and George (George et al, 1991, 1992, and George 1991) have performed extensive studies of nuclear electric propulsion systems for manned exploration missions. The NASA Lewis Research Center's Nuclear Propulsion Office (NPO) has conducted NEP studies and technology development since early in 1990 to support a human presence on the Mars surface in 2019, as recommended by President Bush. Doherty and Holcomb (1993) have summarized the recommendations for NEP technology development made by an interagency panel of NEP experts. NEP systems are also being considered for robotic outer planet science missions. These missions and NEP technology developments are discussed in the Conference Publication from the Nuclear Propulsion Technical Interchange Meeting held in Sandusky, $\mathrm{OH}$ (NP-TIM, 1993). Because of the very high $I_{s p}$ (specific impulse) which leads to low propellant requirements, NEP systems are believed to be enabling for a wide range of possible future planetary missions - both manned and robotic. 


\section{Propulsion System Selection Criteria}

Prior to selecting a propulsion system for a specific mission, it is important to develop selection criteria and appropriate weighting factors to compare various options on a consistent basis. For example, for a piloted mission to Mars, a number of propulsion system options exist, including: chemical/aerobrake systems (Cohen, 1989); nuclear thermal propulsion systems (Borowski 1991a, 1991b, Borowski and Alexander 1992, 1993, Borowski et al 1992); nuclear electric propulsion systems (Gilland 1991a, 1991b, and 1992); and a "reference" system that utilizes a nuclear thermal rocket (NTR) for earth departure, a Mars-capture-aerobrake, and a liquid oxygen/methane (Lox/CH $)$ chemical rocket stage for return to earth (Duke 1993).

Several possible criteria that could be used to compare these systems include, "better, safer, and cheaper." Metrics must be selected, however, to measure each of the proposed systems against these criteria. For example, "better, safer, and cheaper" could be measured by:

1. Initial mass in low earth orbit (IMLEO): Since this mass (and volume) largely determines the number of heavy lift launch vehicles (HLLV) required to complete the mission, and because the cost involved is on the order of $\$ 1$ billion per launch, this will be a very important metric;

2. Piloted Trip Time: Since the best way to limit the exposure of the astronauts to high energy, intergalactic cosmic radiation is to reduce the time that they spend traveling between earth and Mars and returning, systems that offer reduced trip times are significantly better and safer than slower systems;

3. Safety and Reliability: Since mission failure could result in loss of crew, system safety and reliability will be a critical selection criteria. Obviously, tradeoffs must be made to optimize reliability and safety with robust systems versus redundancy and cost;

4. Abort Options: Some systems offer significantly improved abort options compared to other systems and this metric will be very important. Since loss of crew is an unacceptable mission scenario, systems that permit a safe retum to earth under all foreseeable accident possibilities would be strongly favored over missions that include significant crew risk;

5. Enhanced Science Options: Some systems could offer significantly richer science return as a result of the characteristics of the systems involved. For example, a system that is "power-rich" could enable greater excavation capability, longer crew excursions, more laboratory equipment utilization, and so forth. Maximum science retum could be a selection criteria for the ambitious missions envisioned;

6. Environmental Contamination: Environmental contamination cannot be tolerated, whether on a planetary body, or as part of a ground testing program on the earth, or in space. Mission plans must include acceptable end-of-life disposal for all space hardware, so as not to generate unwanted space debris. This will be a particularly sensitive issue with nuclear systems;

7. Minimum costs: All mission costs must be considered, and in general the more complex the system, the higher the cost. Technology development cost will be a strong function of technology-readiness, and must be traded off against operations cost and technical risk. Detailed development cost will be very important, and flight qualification must be included; these costs will vary from system to system. Total Life cycle cost may be the appropriate metric, and is difficult to predict in advance; and

8. "Unexpected costs:" Unexpected costs probably should also be considered, since these costs may in fact be more important than any of the expected costs. As an example of an unexpected cost, suppose that a nuclear system is planned for the earth departure maneuver, and an unexpected accident occurs that threatens re-entry of the nuclear system into the earth atmosphere. The unexpected cost would be the cost of launching other missions to intercept the system and whatever else is necessary to preclude atmospheric re-entry.

Another unexpected cost example would be the cost of cleanup if a nuclear system did inadvertently re-enter the earth atmosphere and either disperse over a large area or impact the earth intact. These unexpected costs 
must be traded against the probability of occurrence and the benefit to the mission. Also, adverse public opinion regarding possible nuclear system accidents in space could delay or terminate the program.

These proposed metrics are some typical examples of the types of metrics that must be considered in the selection of a propulsion system for a complex mission of this type. Many other metrics will undoubtedly be important as well. A formal decision-making process, such as Quality Functional Deployment - QFD (Bossert 1991, Hauser and Clausing 1988) or the Analytical Hierarchy Process - AHP (Saaty 1980), will be required to (1) identify all the appropriate metrics, (2) apply appropriate weighting factors to each metric, (3) reach consensus on metric scoring for various options, and (4) finally, select the system based on all weighted variables. This formal process will require an appropriate interdisciplinary team of people and a long, consensus-building process to evolve to the optimum selection decision.

\section{REFERENCE MISSION ARCHITECTURE}

Duke, et al (1993) has described several Mars exploration mission architectures, and a set of ground rules by which these architectures can be compared. The current reference mission architecture (as defined by the former Exploration Program Office (EXPO) at NASA Johnson Space Center) is shown schematically in

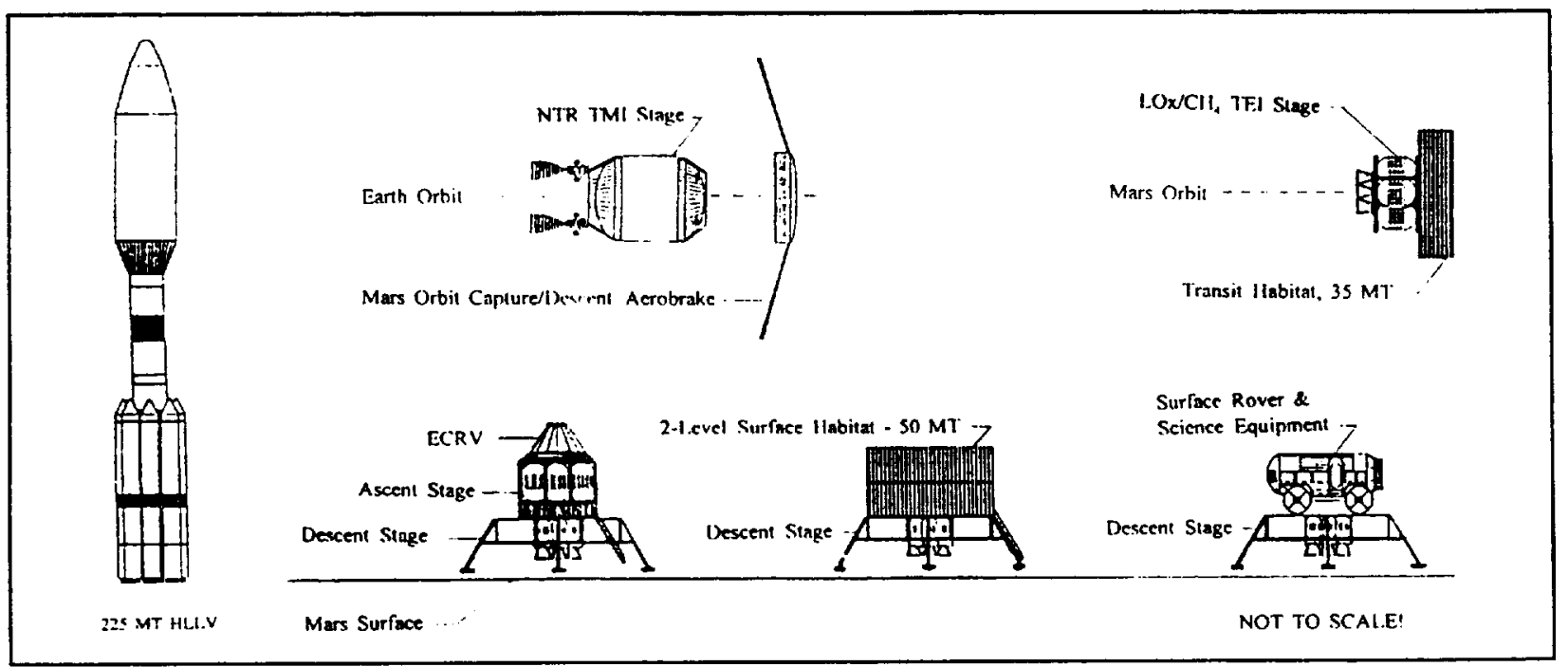

Figure 1. Human Mars Exploration Reference Mission.

Figure 1, and is described in Table I (Duke 1993). This reference architecture provides the mission objectives and common hardware requirements whereby alternative concepts can be compared on a consistent basis. These common requirements are used in this study to evaluate nuclear electric propulsion to perform the same split-sprint mission. Thus, the functionality of the NEP mission must be at least as good as the reference mission.

Common hardware includes: 225 - 240 MT (to low earth orbit) HLLVs; (3) cargo landers (50 MT cargo delivered to Mars each), including an ascent/descent module that includes processing equipment for in-situ resource utilization, a two-level, 50-MT surface habitat, and a surface rover/science equipment module. Each of these modules are delivered to the Mars surface by a nuclear thermal rocket (NTR) Trans-Mars-Injection (TMI) stage, a $29 \mathrm{MT}$ Mars descent aerobrake/parachute system and descent stage designed for a final descent velocity change (delta-V) of $500 \mathrm{~m} / \mathrm{sec}$. The crew travels to Mars in a 50 MT 2-level surface habitat via an NTR TMI stage, a Mars aerocapture aerobrake, and a Mars descent stage. The crew returns to a $\mathrm{LOx} / \mathrm{CH}_{4}$ Trans-Earth-Injection (TEI) stage, including a $35 \mathrm{MT}$ transit habitat, in the 7 MT Earth Crew Return Vehicle (ECRV) for retum to earth. 
There are several issues with respect to the reference mission that should be discussed and (eventually) resolved. First, the heavy lift launch vehicle does not currently exist. Therefore, the lifting capacity, 225-240 MT remains arbitrary. Current studies are also evaluating a $100 \mathrm{MT}$ class HLLV, which would require some low earth orbit rendezvous and docking for the reference mission. For this study, a reference $240 \mathrm{MT}$ HHLV is assumed.

Second, the assumed masses for the transit return habitat (35 MT) and the surface habitat (50 MT) are not well defined. These masses are critical to the entire architecture of the mission.

The nuclear thermal rocket TMI stage does not currently exist, and the cost of ground testing NTR engines in an environmentally acceptable manner remains an issue. Open-air testing of NTR engines will certainly not be acceptable.

The reference mission includes a single aerobrake structure to perform both the Mars orbit capture maneuver and initial deceleration to the Mars landing site. This aerocapture maneuver must be successfully accomplished for both the relatively low velocity cargo payloads and the very high velocity piloted payloads. Successful demonstration of this capability in the Mars atmosphere will undoubtedly be an important (and high cost) element of an aerobrake technology validation experiment.

There is considerable uncertainty in the estimates of the velocity change to be accomplished with the final Mars descent stage. Estimates have ranged from 950 meters/second to as low as 300 meters/second. The current reference mission estimate of $500 \mathrm{~meters} / \mathrm{second}$ is used for this study.

Finally, the reference "abort to Mars surface" strategy requires that redundant surface habitats be available at the site to provide consumables in case the crew is unable to return to the TEI stage and are thus required to stay on Mars until a rescue mission can be sent. Thus, the number of expeditions to a particular site becomes important in determining the number of HLLVs required. For the reference mission, if each expedition is to a different site, five HLLVs would be required per mission opportunity. If two expeditions go to the same site, a total of nine HLLVs would be required, and so forth. For this study and the reference mission, it is assumed that two expeditions go to each site.

\section{NEP STUDY}

The objectives of the NEP split-sprint architecture study were (1) to determine if a nuclear electric propulsion system could be a viable alternative for human Mars exploration missions, (2) to develop an effective NEP implementation and operations strategy, evaluate the system technology requirements, mass estimates and performance parameters, and (3) to provide a first-order estimate of NEP development plans, schedules, and costs. 
The study was performed by staff at the Nuclear Propulsion Office and the Advanced Space Analysis Office at Lewis, with support from NEP technologists at Lewis and JPL. Development cost estimates were made by the Cost Analysis Office at Lewis using Lewis and NASA cost models.

The following groundrules were used to conduct the study:

(1) The reference mission functionality had to be maintained; that is, the necessary infrastructure (150 MT cargo + crew) had to be delivered to the Mars surface on time;

(2) Crew safety and hardware reliability had to be maximized;

(3) The number and/or size of HLLVs had to be minimized to reduce launch costs;

(4) Space-based operations should be kept as simple as possible;

(5) Piloted trip time must be minimized to reduce crew exposure to harmful intergalactic cosmic radiation; and

(6) Life cycle costs must be minimized.

The estimated development costs presented in this report are an important part of the life cycle cost; however, previous studies have shown that transportation costs are the main cost driver for space exploration. Additional studies are underway at NASA in the New Initiatives Office at Johnson Space Center, to compare estimated life cycle costs of various alternative scenarios (Duke 1993).

\section{DESCRIPTION OF NEP ARCHITECTURE}

The NEP mission architecture selected is shown schematically in Figure 2. A nuclear electric propulsion system is used in place of the NTR TMI stage and the TEI LOX/CH 4 stage. NEP propulsive braking is also used to replace the aerocapture Mars orbit insertion maneuver of the reference mission.

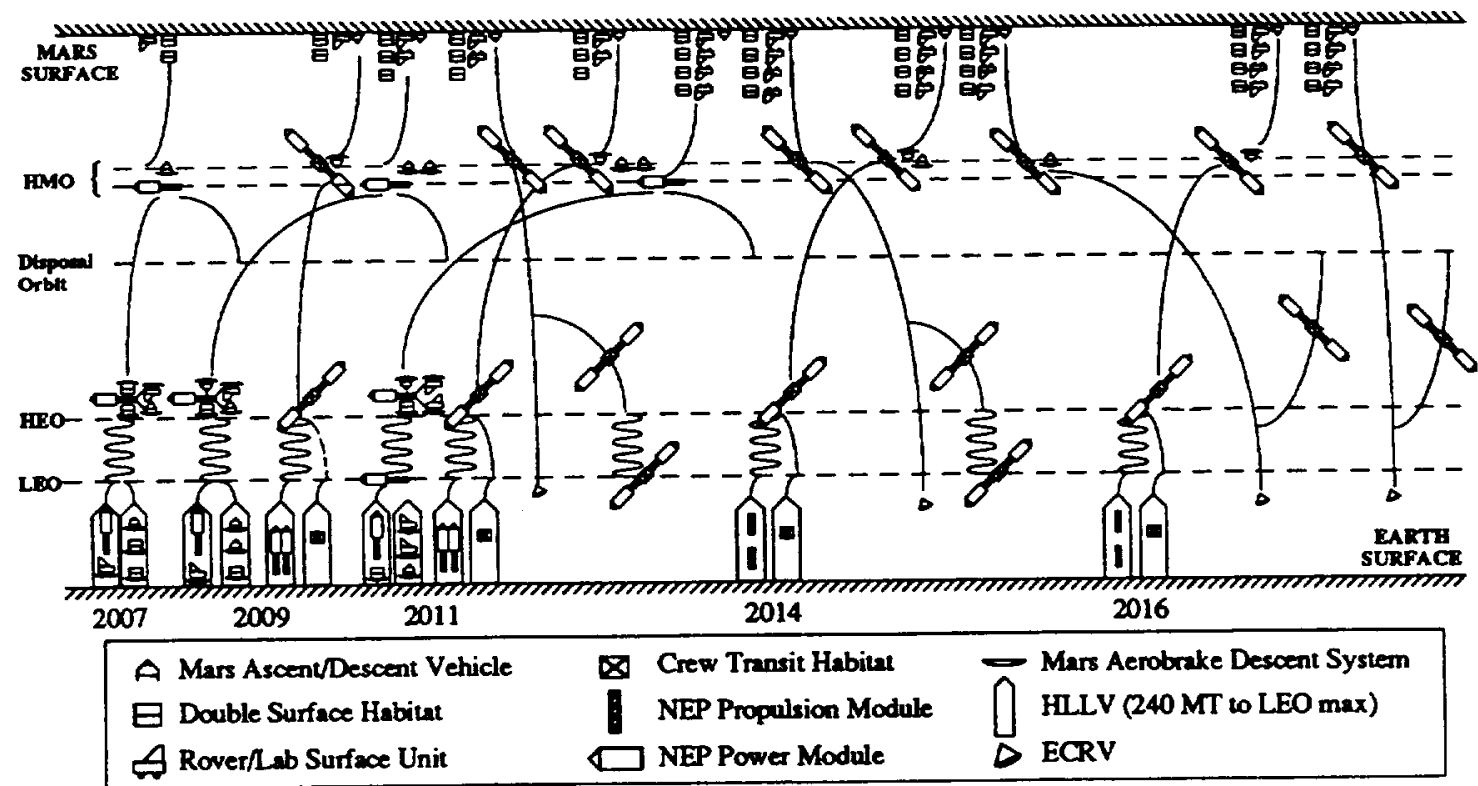

Figure 2. NEP Mission Architecture Shown for Four Mission Opportunities. 


\section{Carroo}

A $4 \mathrm{MW}_{\mathrm{e}}$ reactor/propulsion module is used to transfer cargo on a minimum energy trajectory from low earth orbit $(407 \mathrm{~km})$ to Mars. The NEP system propulsively brakes to Mars orbit capture. As with the reference architecture, an aerodescent and parachute system is used to decelerate each cargo payload to 500meters-per-second descent velocity for which the Mars descent engine is designed. The aerodescent and parachute system are then discarded, and descent engines slow the cargo to hover over the landing site and land autonomously. The NEP cargo stages deliver a surface rover and its related equipment, and two surface habitats. The second habitat is a backup for the first crew in case a problem develops with the ascent vehicle and the crew is required to stay on the Mars surface until a rescue mission can be sent on the next mission opportunity; this habitat would also be used by the crew on the next mission. The NEP cargo stage also delivers a Mars descent/ascent vehicle (without ECRV) to high Mars orbit where it waits for the crew arrival. Once emptied, the NEP propellant tanks are dropped in space to reduce energy requirements - at Earth escape, and upon arrival at high Mars orbit.

In-situ resource utilization (ISRU), $\mathrm{LOx} / \mathrm{CH}_{4}$, for the ascent engine, is replaced in the NEP scenario by a solid propellant ascent stage for several reasons: (1) mass estimates for ISRU versus solid propellants are approximately the same; (2) solid propellants are "off-the-shelf," robust, and simpler (hence, probably more reliable); and (3) the minimum energy trajectories selected for the NEP cargo missions arrive at Mars too late to produce return propellant prior to liftoff of the crew from earth. A smaller ISRU unit may be included on the ascent/descent module if the surface rover is to be powered by $\mathrm{LOX} / \mathrm{CH}_{4}$, or if the ISRU is to be used to provide oxygen for the crew or crop production.

After the NEP systems deploy their cargo at Mars, the NEP module restarts and boosts the vehicle to a heliocentric disposal orbit between earth and Mars $(1.3 \mathrm{AU})$. These systems could perform a very useful communications relay function at this location, insuring that there would be no periods of communications blackout with the crew on the surface of Mars. Solar flare detectors could also be mounted on the vehicle at this location to warn space explorers. Optionally, the NEP propulsion module could be left in Mars orbit as a backup propulsion module for subsequent flights.

\section{Crew}

Two 4-MWe reactor/propulsion modules are used to transfer the crew from earth orbit to Mars on a fast trajectory. One HLLV lifts the NEP propulsion system to low earth orbit. The two power modules are deployed in low earth orbit, and spiral to a high earth orbit (beyond the Van Allen radiation belts) to await the arrival of the crew. A second (lightly loaded) HLLV lifts the crew directly to high earth orbit in a crew command module that includes a $35 \mathrm{MT}$ transfer habitat (with consumables for both transit to Mars and return to the earth), and the ECRV (7 MT). The transfer habitat module (with crew inside) then autonomously docks with the 8-MW, NEP system in high earth orbit, the NEP system is started, and the astronauts continue their journey to Mars. The relatively low mass of the transfer vehicle enables fast transit times with the low thrust NEP system.

The 8-MW $\mathrm{M}_{\mathrm{e}}$ NEP system is also used to propulsively brake into a high Mars orbit (HMO). There, the crew transfers to the ECRV, and the ECRV docks with the descent/ascent stage delivered on the earlier cargo flight, and continues down to the Mars surface to conduct their expedition. The $8 \mathrm{MW}_{e} \mathrm{NEP}$ crew transfer habitat remains in high Mars orbit until the crew completes their surface mission and then returns via the ECRV on the ascent stage, for a return rendezvous with the NEP transfer stage. The crew transfers back to the transit habitat and Trans-Earth Injection (TEI) is then accomplished by the NEP transfer stage. When the maximum ECRV earth-entry velocity of $9.4 \mathrm{~km} / \mathrm{second}$ is reached, the NEP system is turned off, the transit habitat and ECRV separate from the NEP stage; the crew coasts to a direct-entry ocean splashdown in the ECRV. The NEP stage decelerates to capture in high earth orbit $(100,000 \mathrm{~km})$, and then spirals down to low earth orbit ( $1000 \mathrm{~km}$ for resupply) for subsequent refitting for the next mission. This refitting includes NEP propellant tanks and thrusters for the next piloted trip. Upon completion of the retrofitting, the NEP stage spirals out to high earth orbit to await the arrival of the next crew. 
The HLLV launch manifests for the 2009, 2011, 2014 and 2016 mission opportunities are shown in Table II. The most heavily loaded launch at $240 \mathrm{MT}$ is the "Piloted A" launch that sends the NEP power and propulsion system to low earth orbit. Notice that the "Piloted B" launch carries the crew in the $35 \mathrm{MT}$ transit habitat with an earth crew return vehicle (ECRV) to high earth orbit for rendezvous with the assembled NEP transportation stage. It may be possible to use a smaller launch vehicle for this earth-to-orbit crew ascent leg of the mission. Attaching the ECRV to this launch permits a direct return to earth if a problem develops prior to earth escape. Assuming that two crews visit each expedition site (as discussed above), the reference architecture requires $41 / 2$ HLLVs per mission opportunity ( 9 HLLV for two opportunities). The NEP architecture described above requires only $31 / 2$ HLLVs per mission opportunity - a savings of one HLLV every 26 months. Since each HLLV will probably cost $\$ 1$ billion or more, this represents a very large cost savings!

\section{NEP SYSTEM}

The NEP piloted vehicle configuration is shown schematically in Figure 3. Two $4 \mathrm{MW}_{\mathrm{c}}$ nuclear power systems provide the thermal energy. The cargo propulsion and power modules are exactly the same, but only one module is used for the cargo flights. SP-100 reactor technology is assumed - scaled up in power from $2.4 \mathrm{MW}_{1}$ to $24 \mathrm{MW}_{\mathrm{t}}\left(100 \mathrm{kw}_{\mathrm{e}}\right.$ to $4 \mathrm{MW}$ ), with a 5-year full power life. Each reactor is separated from the crew by shielding and a 60 -meter long boom - limiting crew radiation from the reactors to less than $5 \mathrm{Rem} / \mathrm{year}$. The uranium nitride pin-type fuel is cooled with liquid lithium in a fast reactor configuration. Reactor outlet temperature is $1375 \mathrm{~K}$. A potassium-rankine turbine-alternator system is used (turbine inlet temperature $1300 \mathrm{~K}$ ) to generate electrical power at 1400 volts

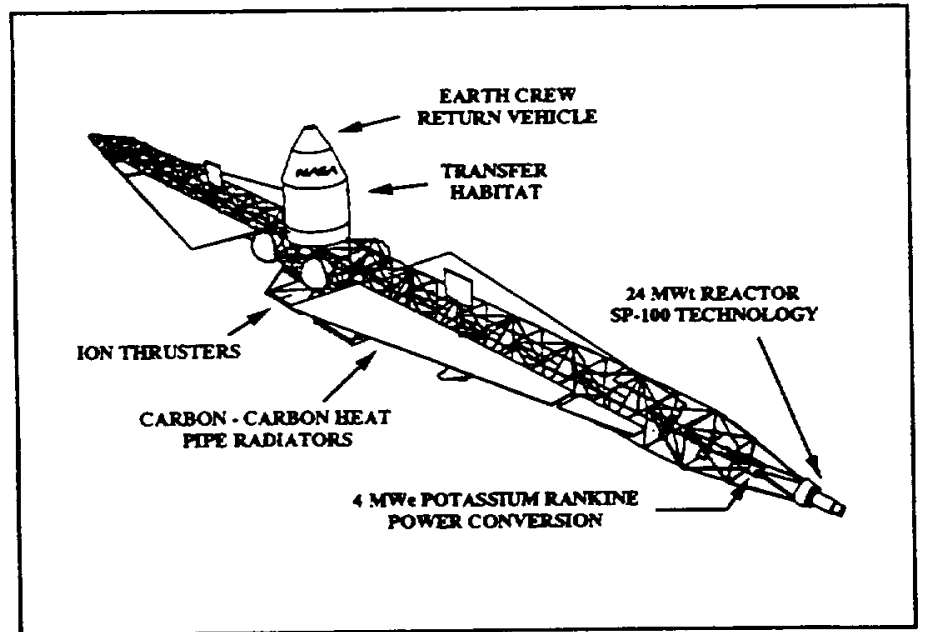

Figure 3. 8 $\mathrm{MW}_{\mathrm{e}}$ Piloted Mars Vehicle.
Table II. HLLV Launch Manifests for Four NEP Mission Opportunities to Mars.

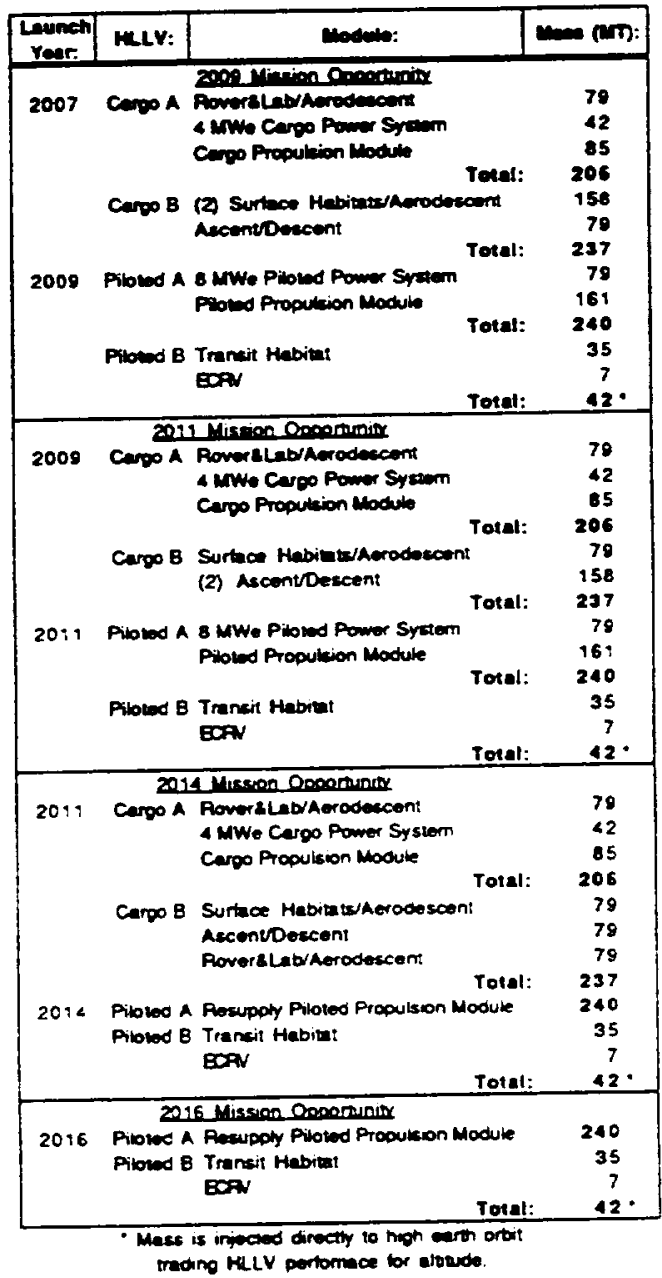

and $2 \mathrm{kHz}$, and transmit the electricity to the power conditioning equipment. Three $2-\mathrm{MW}_{\mathrm{c}}$ power conversion loops are included for a 50-percent redundancy of the power conversion system. Carbon-carbon-potassium heat pipe radiators reject waste heat from the rankine cycle at temperatures approaching the $975 \mathrm{~K}$ condensing temperature of the potassium. Mass estimates for the radiator are based on $5 \mathrm{~kg} / \mathrm{m}^{2}$ for the radiators and condensers, which is consistent with SP-100 technology. An additional $1 \mathrm{~kg} / \mathrm{m}^{2}$ is included for the tapered shear flow condenser duct running along the base of each radiator "wing." In the power management and distribution (PMAD) system, high temperature $(450 \mathrm{~K})$ electronics convert the electricity to the form required for the banks of $1000 \mathrm{~kW}$ ion thrusters. Two PMAD architectures were investigated. Generation and transmission at 
the 1400 volt load requirement proved to be lighter than generation and transmission at 5000 volts. Although the high voltage option would have high transmission efficiency, this was more than offset by the transformer mass required. The propellants assumed are krypton for the piloted flights and argon for the cargo flights.

Table III. NEP system Mass Breakdown (kg) for 2009 Mission Opportunity.

\begin{tabular}{|c|c|c|}
\hline & $\begin{array}{c}\text { CARGO } \\
\text { VEHICLE }\end{array}$ & $\begin{array}{l}\text { PLOTLD } \\
\text { VEHICLE }\end{array}$ \\
\hline Power Module & $1 \times 4 \mathrm{MWe}$ & $2 \times 4 \mathrm{MWe}$ \\
\hline Reactor & 3.810 & $\mathbf{7 . 6 2 0}$ \\
\hline Shield & 9,760 & 19.520 \\
\hline Power Conversion & 7,860 & 15,720 \\
\hline Radiator & 4,180 & 8,360 \\
\hline Power Conditioning & 11,250 & 22,500 \\
\hline Bus/Boom/Srmcture & 4.650 & 5,400 \\
\hline Total & 41,510 & 79,120 \\
\hline Ion Propuksion Module & $3 \times 4 \mathrm{MWe}$ & $4 x 4 \mathrm{MWe}$ \\
\hline Thruster/Power Processing & 7,200 & 9,600 \\
\hline Propellant & 65,650 & 137,460 \\
\hline Tankage & 6,570 & 13,750 \\
\hline Stnucture & 6.000 & 1200 \\
\hline Total & 85,420 & 162,010 \\
\hline Paylond & 316,000 & $42, A B A$ \\
\hline Total & 42,930 & 283,130 \\
\hline
\end{tabular}

A component by component system mass breakdown is shown in Table III for the 2009 mission opportunity. Masses for other less demanding missions would be the same, except for the propellant requirement which would be less. Note that for the cargo vehicle, one $4 \mathrm{MW}$ power module and three 4 $\mathrm{MW}_{\mathrm{e}}$ thruster modules are required. For the piloted vehicle, two $4 \mathrm{MW}_{\mathrm{e}}$ power modules and four $4 \mathrm{MW}_{\mathrm{e}}$ thruster modules are required. Also, since the piloted vehicle is also planned to be used for a second mission opportunity, the thruster modules and propellant must be resupplied between missions.

\section{MISSION ANALYSIS}

The mission analysis was performed using the low-thrust mission analysis code VARITOP (Sauer 1991). VARITOP is a two-body heliocentric planetary trajectory code written for low thrust mission optimization and design. Earth spiral trajectories were estimated using an Edlebaum-Fimple method (Fimple and Edelbaum 1964). Transit times and stay time at Mars were calculated to minimize the piloted trip time.

Results of the optimization calculations are shown in Figure 4 for the 2009 (worst case) piloted mission. Figure 4 shows that the minimum total piloted trip time is a function of available

HLLV size and NEP system power. For a 240-MT HLLV, the optimum power of $8 \mathrm{MW}_{\mathrm{e}}$ results in a piloted trip time of 390 days. Two $4 \mathrm{MW}_{\mathrm{e}}$ power modules were thus selected for the piloted NEP vehicle, and a single $4 \mathrm{MW}_{\mathrm{e}}$ power module was selected for the cargo vehicle.

The results of the mission study are summarized in Figure 5 for the four piloted mission opportunities from 2009 to 2016 . It is assumed that the missions in 2009 and 2011 are at the same site, and the missions in 2014 and 2016 visit a different site. Actual transit times and important mission dates are summarized in Table IV. These transit times are very comparable to the estimated transit times for the reference mission which are about 180 days each way in the 2009 opportunity.

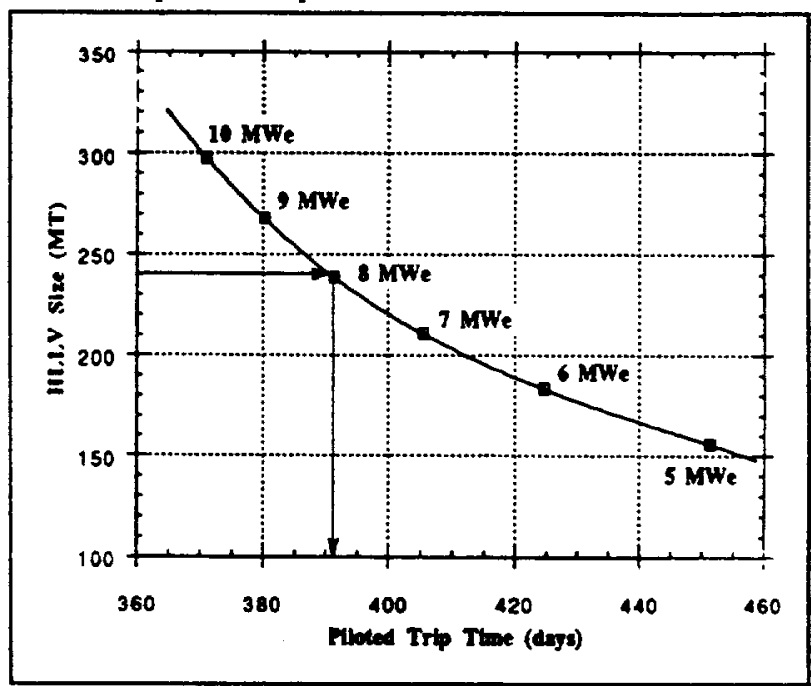

Figure 42009 Piloted Mission Performance.

\section{TECHNOLOGY REQUIREMENTS}

The proposed NEP technology development schedule is shown in Figure 6. Major milestones for development of the technologies required for the NEP system and missions described in this paper include: (1) component technology validation complete [technology readiness level 4 - (TRL-4)] by 1999, and (2) subsystem technology validation complete (TRL-5) by 2001. A sustained technology development program and parallel systems engineering effort will be required to meet these milestones. Unfortunately, development of both nuclear and non-nuclear technologies is currently not being funded for these exploration missions by either NASA or DOE. 


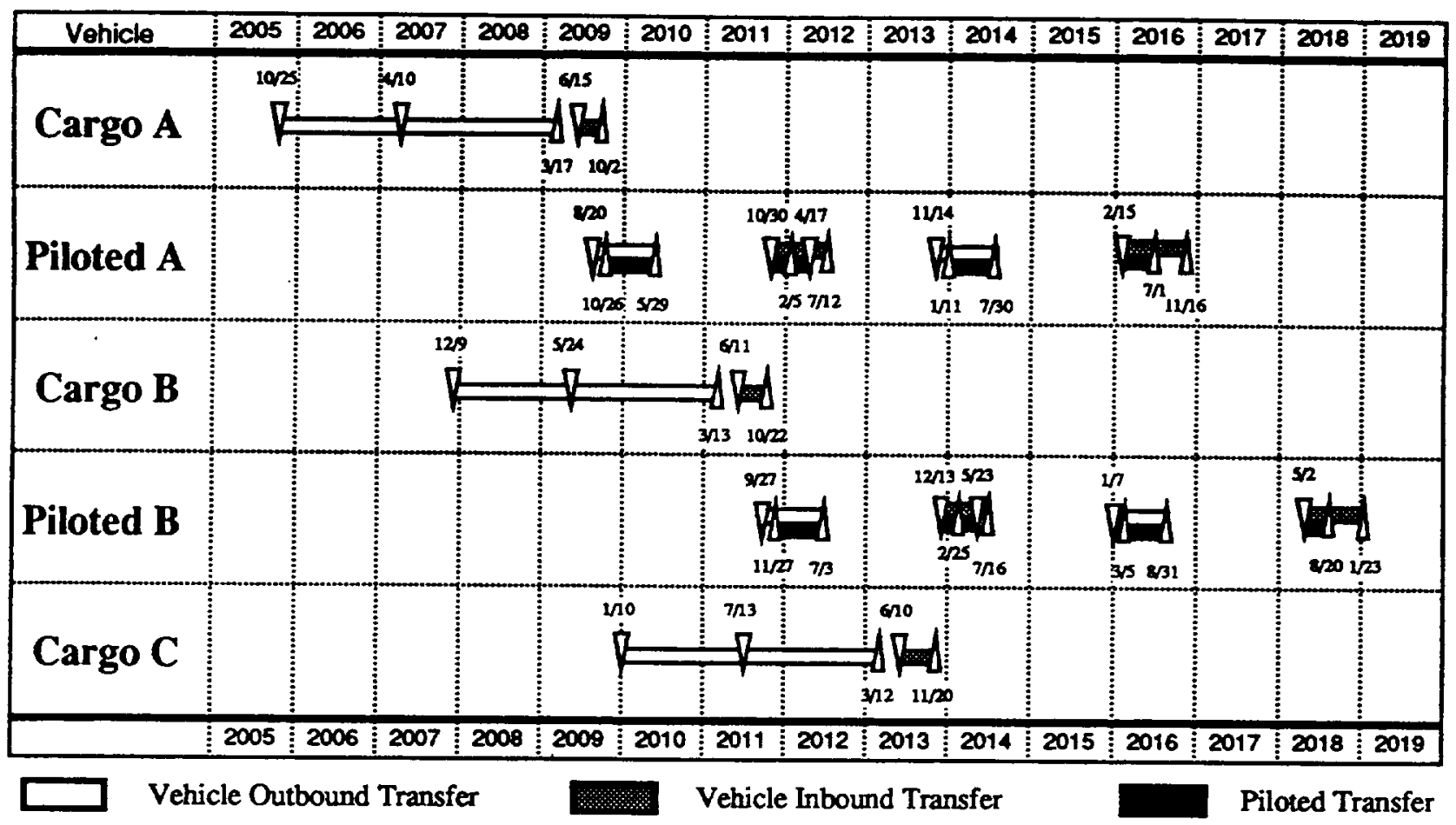

Figure 5. NEP Split-Sprint Mission Time-lines

\section{Reactor}

Starting from the current SP-100 technology baseline, a $25 \mathrm{MW}_{\mathrm{th}}(4 \mathrm{MW}) \mathrm{UN}$ pin-type fast reactor must be designed, built and tested. While some UN fuel pins have been fabricated in the SP-100 program, no significant fuel production capability currently exists in this country. Significant effort will be required to develop repeatable, quality-assured, low-cost fabrication processes for a sustained space nuclear exploration program. Manufacturing technology must be included in this program to ensure meeting cost and performance goals. Important elements of the reactor technology development program include: (1) scaleup (from $2.4 \mathrm{MW}_{1}$ to $24 \mathrm{MW}_{\mathrm{t}}$ ) and validation of all of the reactor components including thermoelectromagnetic (TEM) pump, gas separator, shield, and control drive assembly; (2) failure mechanism and life testing of all components; and (3) technology validation of the reactor at outlet temperatures of $1375 \mathrm{~K}$ and a five-year reactor operating life, with adequate design margins, and appropriate instrumentation, controls and health management systems to ensure reactor integrity over all anticipated operating conditions. Several experimental reactor test sites in this country have been identified in which reactor sub-system ground tests could be conducted after modification, including the SP-100 Ground Test Facility in Hanford, WA, Building 6580 at Sandia, the experimental gas-cooled reactor facility at Oak Ridge, or the LOFT facility at INEL (Doherty and Holcomb, 1993). Modification of one of these facilities will be a major cost factor for the technology development of the reactor. Existing facilities abroad should also be considered. This could be an area for significant international cooperation. Reactor technology development costs are not included in this report, since this technology will be developed as part of the nuclear surface
Table IV. NEP Piloted Trip Time versus Mission Opportunity.

\begin{tabular}{|c|c|c|c|c|}
\hline $\begin{array}{l}\text { Vehicle } \\
\text { Mission: } \\
\end{array}$ & $\begin{array}{c}\text { Piloted A } \\
2009 \text { Piloted }\end{array}$ & $\begin{array}{c}\text { Piloted B } \\
2011 \text { Piloted }\end{array}$ & $\begin{array}{c}\text { Piloted A } \\
2014 \text { Piloted }\end{array}$ & $\begin{array}{c}\text { Piloted B } \\
\text { 2016 Piloted }\end{array}$ \\
\hline \multirow{6}{*}{ 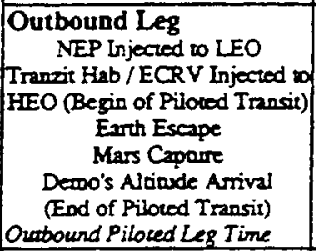 } & & & & \\
\hline & $8 / 20 / 2009$ & $9 / 27 / 2011$ & $11 / 14 / 2013$ & $1 / 7 / 2016$ \\
\hline & $10 / 20 / 2009$ & $11 / 272011$ & $1111 / 2014$ & $315 / 2016$ \\
\hline & $\begin{array}{c}10 / 26 / 2009 \\
5 / 24 / 2010\end{array}$ & $\begin{array}{l}12 / 2 / 2011 \\
629 / 2012\end{array}$ & $\begin{array}{l}1 / 16 / 2014 \\
7 / 26 / 2014\end{array}$ & $\begin{array}{l}3 / 11 / 2016 \\
8 / 27 / 2016\end{array}$ \\
\hline & $5 / 29 / 2010$ & $7 / 3 / 2012$ & 713012014 & $8 / 31 / 2016$ \\
\hline & 220.7 & 219.7 & 1928 & 178.5 \\
\hline \multirow{7}{*}{ 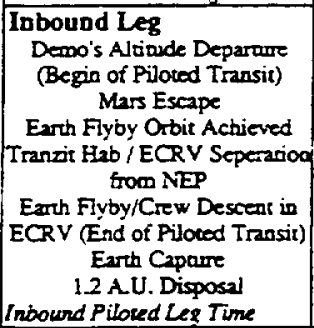 } & & & & \\
\hline & 1013012011 & $12113 / 2013$ & $2 / 18 / 2016$ & $5 / 2 / 2018$ \\
\hline & $11 / 3 / 2011$ & $12 / 17 / 2013$ & $221 / 2016$ & $5 / 5 / 2018$ \\
\hline & $1 / 12 / 2012$ & $2 / 22 / 2014$ & - & \\
\hline & $2 / 4 / 2012$ & $2 / 25 / 2014$ & $N / A$ & $N / A$ \\
\hline & $4 / 18 / 2012$ & 5232014 & $711 / 2016$ & $8 / 22 / 2018$ \\
\hline & $\begin{array}{c}7 / 12 / 2013 \\
\text { N/A } \\
170 \text { ? }\end{array}$ & $\begin{array}{c}7 / 162014 \\
\text { N/A } \\
\text { 161.4 }\end{array}$ & $\begin{array}{c}11 / 16 / 2016 \\
1339 \\
\end{array}$ & $\begin{array}{c}1 / 26 / 2019 \\
1117\end{array}$ \\
\hline $100 \mathrm{all}$ & 390.9 & 381.1 & 333.7 & 290.2 \\
\hline
\end{tabular}




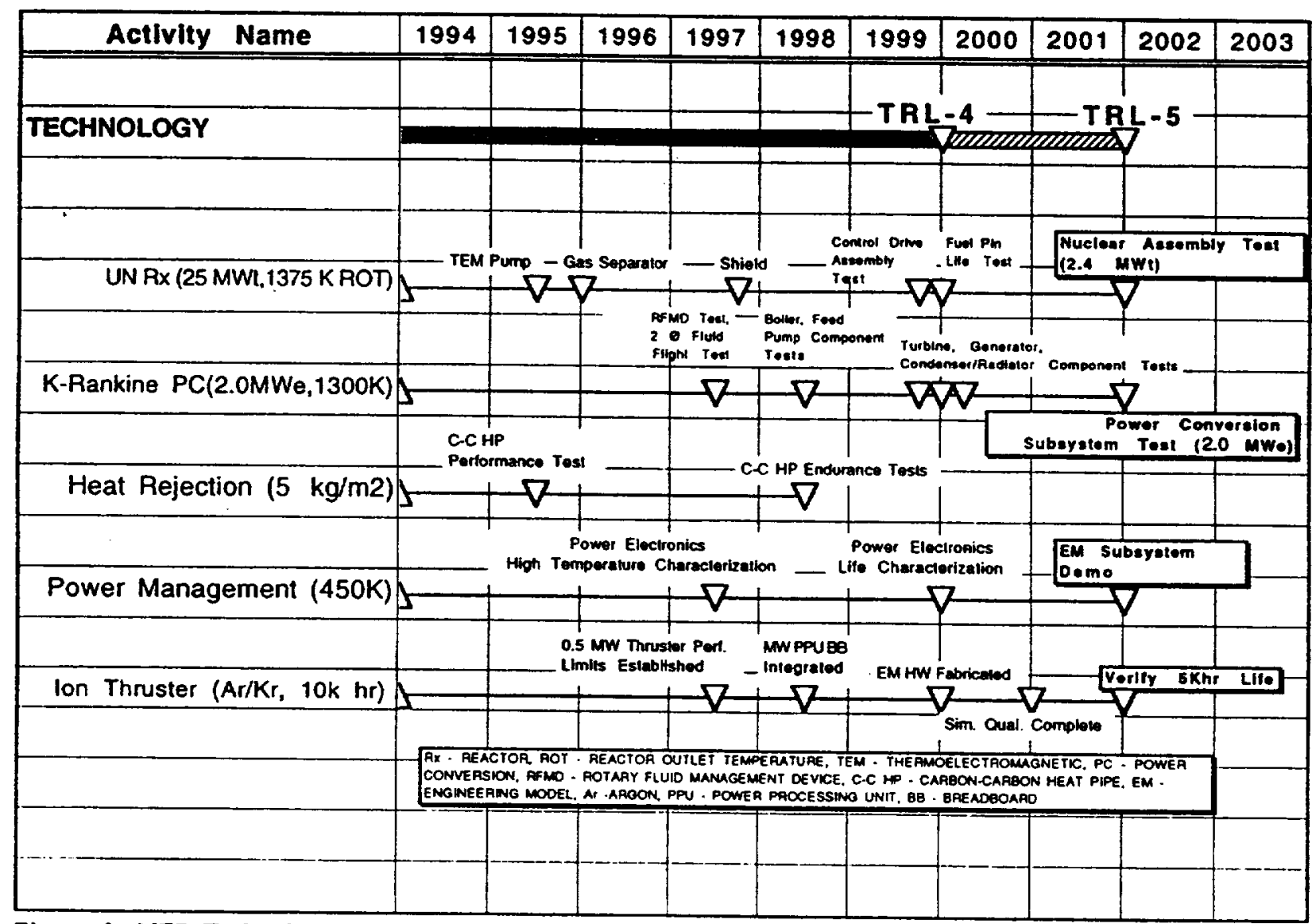

Figure 6. NEP Technology Development Schedule.

power program. No non-nuclear facility modification costs are included in the technology development cost estimates either, since existing (non-nuclear) facilities exist.

\section{Potassium-Rankine Power Conversion System}

While some technology development for two-phase Potassium-Rankine systems has occurred in the past, much work remains to flight-qualify these systems for these demanding missions. While the temperatures suggested $(1300 \mathrm{~K})$ will not require exotic composite or ceramic materials (just refractory metal alloys), the long life and reliability requirements will be design challenges. Issues include operation of a boiling potassium system in zero-gravity, start-up and shutdown control, and minimizing system mass. A two-phase fluid flight test and a "rotary fluid management device" (RFMD) test are recommended by 1997 to demonstrate boiling potassium phenomenon, followed by boiler, feed pump, turbine, generator, and condenser/radiator component tests. Technology validation of the complete power conversion subsystem ( $2 \mathrm{MW}_{\mathrm{e}}$ ) must be complete by the end of 2001 .

\section{Heat Rejection}

The heat rejection system radiates waste heat from the power conversion system to black body space. Carbon-carbon heat pipe radiators are proposed for the NEP system to reduce mass to $5 \mathrm{~kg} / \mathrm{m}^{2}$ or less. Performance, life and deployment are critical technology issues. 


\section{Power Manaqement}

Power management and distribution systems condition, transmit and process the electrical power used by the thrusters to propel the NEP system. While the current state-of-the-art for these systems limits operating temperature to about $300 \mathrm{~K}$, it is proposed that 5-year-life, $450 \mathrm{~K}$ systems will be required to reduce mass requirements for this important component. The higher temperatures, which should be attainable with gallium arsenide, aluminum gallium arsenide, or silicon carbide electronic components, will permit lighter weight heat rejection assemblies associated with these components.

\section{Ion Thrusters}

Steady state electrostatic ion thrusters are proposed for the NEP system. Krypton is the propellant proposed for the piloted flights, and Argon is recommended for the cargo flights. In the thruster, the propellant atoms are ionized by electron bombardment and the resultant ions are accelerated to high velocities by an electrostatic field applied between two closely spaced electrodes (Doherty and Holcomb, 1993). The exhaust beam of positive ions is neutralized by electron injection. A steady state power source is required supplying kilovolts at ten to hundreds of amperes. Krypton thrusters are expected to operate with efficiencies from 70 to over 80 percent and specific impulse from 4000 to 7000 seconds. Argon thrusters are expected to operate from 75 to 82 percent efficiencies and specific impulses of 5000 to 10,000 seconds. Scaling of current ion thrusters to megawatt levels will require development of large area grids and hollow cathodes capable of operating at hundreds to thousands of amperes for thousands of hours. For this study, the specific impulse was optimized, and a thruster lifetime of 10,000 hours was assumed, requiring that the thrusters (and propellant) be replaced after each piloted trip to Mars.

\section{NEP FLIGHT SYSTEM DEVELOPMENT}

The proposed schedule for NEP flight system development is shown in Figure 7. Concept definition and system trade studies, and development Phase A/B studies will be conducted in parallel with the technology

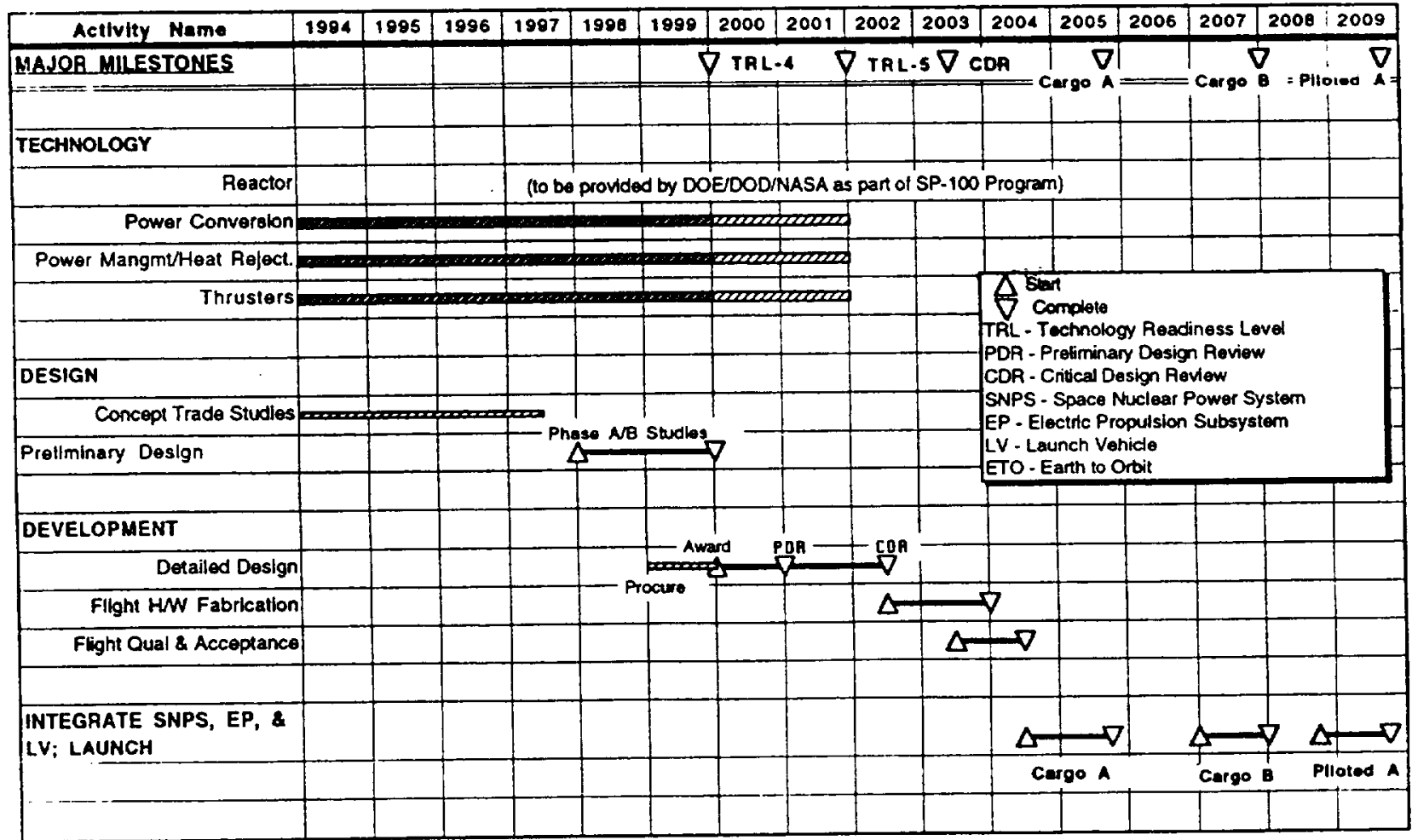

Figure 7. NEP System Development Schedule for Mars Piloted Exploration Missions. 
development described above. Phase $C / D$ contracts should be awarded in 2000 for detailed flight designs, hardware fabrication, and flight qualification/acceptance testing. A preliminary design review (PDR) will be held in 2000, and a critical design review (CDR) in 2002. Integration of the NEP space nuclear power subsystem (SNPS) and propulsion subsystem with the launch vehicle will occur in 2004 and 2005, to launch the first earth-to-orbit (ETO) cargo flight (Cargo A) in October, 2005. No precursor flight demonstration of the full system has been included in this schedule or cost estimate, but probably should be considered to increase confidence prior to first cargo launch to Mars.

Estimated cost of the non-nuclear technology development, flight system development, and flight hardware fabrication are summarized in Figure 8. It is assumed that the Department of Energy will develop NEP nuclear technology and nuclear test facilities as part of the nuclear surface power development program. NASA will provide technology development for the balance of the system (estimated to cost about $\$ 721 \mathrm{M}$ in 1993 dollars), and system integration. The estimated cost of the Phase A/B studies ( $\$ 154$ M) includes 3-4 parallel contracts to evaluate various NEP system options. Flight system development costs (\$2.8 B) include a single Phase $C / D$ contract. The technology development and Phase $A / B$ activities prior to Phase $C / D$, include a 10 percent Program Office reserve, and a center program support charge of 25 percent for technology development and Phase A/B activities. Similarly, for the flight development activities (Phase C/D), the cost estimates include development, fabrication and test of the flight hardware. This system is assumed to be "astronaut-rated." Based on a NASA cost estimation system that accounts for technology readiness and other uncertainty factors, a 30 percent contingency has been added. A contractor fee of eight percent is assumed, and five percent program support is added. It is assumed that only one full power system will be required prior to first flight for system qualification. Subsystem hardware is included for testing at the subsystem level. The cost estimate does not include costs associated with integration of the system into a launch vehicle at Cape Kennedy, launch operations, or costs of mission operations. These costs must also be included to compare life cycle costs of various systems. Fabrication of flight hardware for the four mission opportunities, 2009, 2011, 2014, and 2016 are estimated to cost about $\$ 7.8 \mathrm{~B}$.

\section{DISCUSSION OF RESULTS}

Several advantages are apparent for the NEP split-sprint mission scenario proposed:

(1) Development of the NEP transportation system should significantly reduce the overall life cycle cost for the piloted exploration of Mars. The NEP system would replace the NTR TMI stage, and the LOx/CH $/ \mathrm{CH}_{4}$ TEI stage, and simplify and significantly reduce the development cost and uncertainty of the Mars aerocapture device, since the initial Mars atmospheric entry velocity can be controlled and would be the same for both cargo and piloted payloads. Development of the $\mathrm{LOx} / \mathrm{CH}_{4}$ ascent stage would be replaced with a simpler solid propellant ascent stage. While recurring unit costs of the NEP system are higher than comparable NTR costs, these costs are more than offset by savings in HLLV costs and the reduced number of systems required. HLLV costs could be reduced by about $\$ 1 \mathrm{~B}$ per mission opportunity as Figure 8. Estimated NEP System Development Costs for Split-

a result of reducing HLLV requirements Sprint Piloted Mars Missions. by one launch per opportunity. This

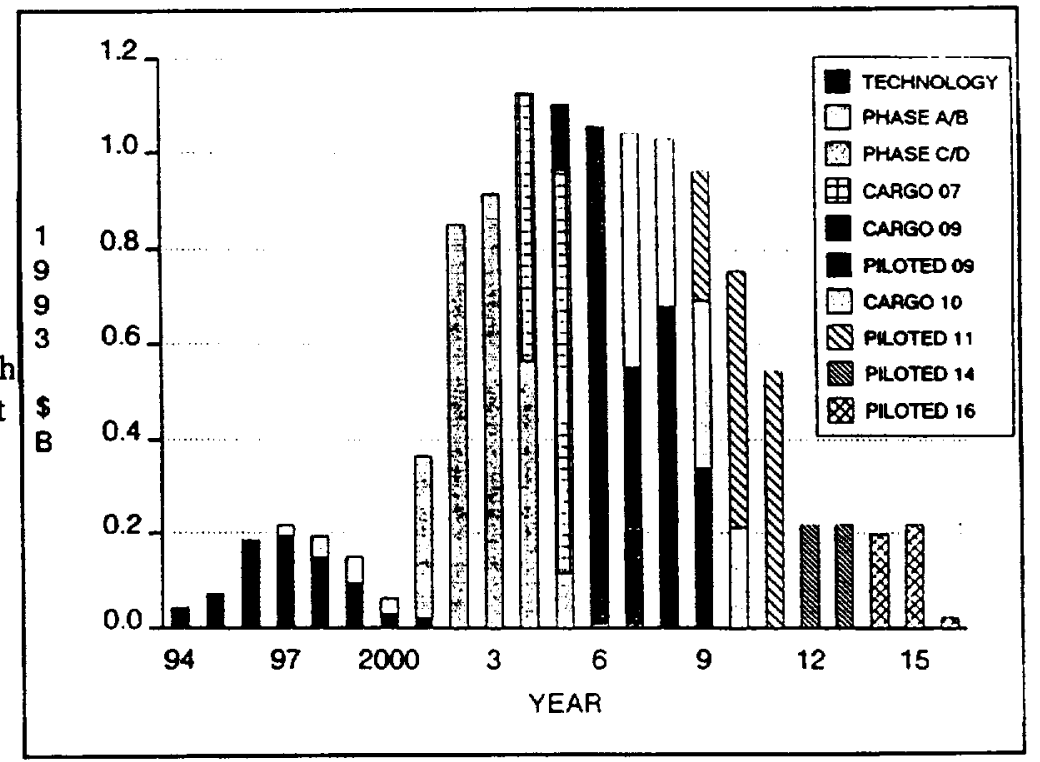


assumes a HLLV cost of at least $\$ 1 \mathrm{~B}$ per vehicle; savings would be proportionately higher if HLLV costs are higher;

(2) Propulsive NEP braking to a circular Mars orbit could provide a significant advantage over the reference mission highly elliptical orbit, enabling access to much more of the planet surface. Docking maneuvers in Mars orbit would also be easier, enhancing astronaut safety;

(3) The reference mission does not include a means for abort back to earth; all aborts deliver the astronauts to the Mars surface and rescue in the next mission opportunity twenty-six months later. The NEP scenario, with the earth crew return vehicle (ECRV) included on the piloted vehicle, ensures a means to return to the earth if an abort is required prior to departure from earth orbit, or in the event of a swing-by abort at Mars;

(4) The high specific impulse of the NEP system results in significantly lower propellant requirements, and reduced IMLEO. Cryogenic liquid hydrogen storage and handling problems would be eliminated both on the ground at the launch site, and for long term storage in space;

(5) Development of the NEP system would be a first step toward exploration of planets beyond Mars. Because of the distances involved, very high specific impulse systems and low propellant requirements will be required. Precursor NEP missions to the outer planets could provide the flight testing of NEP systems with robotic payloads, thus validating the propulsion system and conducting meaningful science missions;

(6) Several possible environmental issues are eliminated by developing the NEP system. Since the nuclear thermal rocket would not be required, NTR ground testing would not be an issue. Also, end-of-life disposal of NEP systems is straightforward; very little additional propellant is required to place the system in a $1.3 \mathrm{AU}$ orbit with no chance of reencounter with earth;

(7) Total transfer time from earth orbit to Mars orbit and return are very comparable to the reference mission trip times, thus minimizing the crew exposure to intergalactic cosmic radiation; and

(8) The NEP power and propulsion modules used to deliver the cargo to Mars orbit may be used for other purposes after the cargo departs for the Mars surface. The modules could be left in Mars orbit as a backup for returning the crew to earth. The module could include scientific instruments to accomplish other important functions after deployment to the disposal orbit, such as monitoring solar flare activities, or relaying communications from Mars to earth. The additional mass required to accomplish these functions could easily be included on these flights.

The benefits of an NEP system are not without a price:

(1) Rendezvous and autonomous docking of the NEP system and Mars surface modules in Earth orbit will be required to take advantage of the NEP performance characteristics. The reference mission also requires rendezvous and docking in Mars orbit, so relatively little additional development cost should be required;

(2) NEP technology (power conversion, thrusters, radiators) is currently not as well known as chemical propulsion or nuclear thermal propulsion, so technical risk and uncertainty are higher; and

(3) The NEP development program proposed does not include a precursor full system flight test that would be the first test of the power reactor module and the electric thruster module. This may present an unacceptable risk on the first Mars cargo mission; a robotic precursor mission is strongly encouraged to validate the full system. 


\section{ADDITIONAL STUDIES}

There are probably more effective ways of integrating the $4 \mathrm{MW}$ power modules, power conversion equipment, waste heat radiators, electric thrusters, and payload modules into a functional, deployable vehicle, with minimum space assembly. Very little effort was expended in this important area in this study.

The reference mission abort to Mars surface strategy requires that a backup surface habitat (50 MT) be provided at each exploration site. Perhaps a less costly option would provide a redundant ascent stage at each exploration site, at considerable mass savings. The crew could then abort to the NEP system in Mars orbit, and return safely to the earth.

There may be other launch vehicle options that could deliver the crew and transfer habitat to high earth orbit. If a smaller launch vehicle could be used in place of a HLLV, considerable cost savings could result.

System component redundancy remains an issue that must be studied. In the scenario presented, redundant power conversion equipment is included. Improved reliability of these and other components could contribute to lower overall system mass and hence, reduced cost.

\section{Acknowledgments}

This study was conducted at the NASA-Lewis Research Center and was supported by the NASA Headquarters Office of Advanced Concepts and Technology. The authors would like to acknowledge our colleagues from around the country within NASA, DoD, DOE, industry and academia that have worked closely with us in formulating project plans over the past several years.

\section{$\underline{\text { References }}$}

S.K. Borowski, (1991a) "The Rationale/Benefits of Nuclear Thermal Rocket Propulsion for NASA's Lunar Space Transportation System," ALAA 91-2052

S.K. Borowski, (1991b) "An Evolutionary Lunar-to-Mars Transportation System Using Modular NTR/Stage Components," AIAA 91-3573

S.K. Borowski and S.W. Alexander, (1992) "Fast Track" NTR System Assessment for NASA's First Lunar Outpost Mission, AIAA-92-3812

S.K. Borowski, and S.W. Alexander, (1993) "Nuclear Thermal Rocket/Vehicle Design Options for Future NASA Missions, AIAA 93-1945

S.K. Borowski, J.S. Clark, R. J. Sefcik, R.R. Corban, and S.W. Alexander, (1992) "An Accelerated Development, Reduced Cost Approach to Lunar/Mars Exploration Using a Modular NTR-Based Space Transportation System," IAF-92-0574

J. L. Bossert, (1991) Quality Functional Deployment - A Practitioner's Approach ASQC Quality Press, Milwaukee

A. Cohen, (1989) "Report of the 90-Day Study on Human Exploration of the Moon and Mars," NASA, Washington, DC 20546

M.P. Doherty (NASA-LeRC) and R.S. Holcomb (ORNL), (1993) "Summary and Recommendations on Nuclear Electric Propulsion Technology for the Space Exploration Initiative," NASA TM 105707 
M.B. Duke, P.W. Keaton, D. Weaver, B. Roberts, G. Briggs and W. Huber, (1993) "Mission Objectives and Comparison Strategies for Mars Exploration," AIAA 93-0956

M.B. Duke, (1993) "Mars Exploration Strategies: A Reference Program and Comparison of Alternate Architectures," IAF-93-2.1.383

W.R. Fimple and Edelbaum, T.N. (1964), "Applications of SNAP-50 Class Powerplants to Selected Unmanned Electric Propulsion Missions," AIAA 64-494

J.A. George, K.J. Hack, and L.A. Dudzinski, (1991), "Fast Piloted Missions to Mars Using Nuclear Electric Propulsion," AIP CONF-910116, Proc. Eighth Symposia on Space Nuclear Power Systems

J.A. George, (1991), "Multimegawatt Nuclear Power Systems for Nuclear Electric Propulsion," AIAA $91-3607$

J.A. George, K.J. Hack, L.A. Dudzinski, L.P. Gefert, and J.H. Gilland, (1992), "Piloted Mars Mission Planning: NEP Technology and Power Levels," AIP CONF 92-246, Proc. Ninth Symposia on Space Nuclear Power Systems

J. H. Gilland, (1991a) "Mission and System Optimization of Nuclear Electric Propulsion Vehicles for Lunar and Mars Missions," NASA CR 189058, IEPC-91-038

J.H. Gilland, (1991b) "NEP Mission Sensitivities to System Performance," NASA CR 189059

J.H. Gilland, (1992) "Synergistic Use of High and Low Thrust Propulsion Systems For Piloted Missions to Mars," NASA CR 189138, AIAA-91-2346

J.R. Hauser and D. Clausing, (1988), "The House of Quality," Harvard Business Review, Pg 63-73, MayJune, 1988

NP-TIM, (1993) "Nuclear Propulsion Technical Interchange Meeting, Volumes I and II," NASA CP 10116, Meeting held in Sandusky, OH October 10-12,1992

T.L. Saaty, (1980), The Analytical Hierarchy Process, McGraw-Hill

C.G. Sauer, Jr. (1991), "A Users Guide to VARITOP, A General Purpose Low-Thrust Trajectory Optimization Program, Jet Propulsion Laboratory, Advanced Propulsion Group, Pasadena, CA 91109 
Public reporting burden for this collection of information is estimated to average 1 hour per response, including the time for reviewing instructions, searching existing data sources, gathering and maintaining the data needed, and compteting and reviewing the collection of information. Send comments regarding this burden estimate or any other aspect of this Davis Highway, Suite 1204. Allington, VA 22202-4302, and to the Office of Management and Budget, Papemork Recuction Project (0704-0188), Washington, DC 20503.

\begin{tabular}{l|l|l} 
1. AGENCY USE ONLY (Leave blank) & $\begin{array}{c}\text { 2. REPORT DATE } \\
\text { March } 1994\end{array}$ & $\begin{array}{r}\text { 3. REPOFT TYPE AND DATES COVERED } \\
\text { Technical Memorandum }\end{array}$
\end{tabular}

\section{TITLE AND SUBTTILE}

5. FUNDING NUMBERS

Nuclear Electric Propulsion: A "Better, Safer, Cheaper" Transportation

System for Human Exploration of Mars

\section{AUTHOR(S)}

WU-593-71

John S. Clark, Jeffrey A. George, Leon P. Gefert, Michael P. Doherty, and Robert J. Sefcik

7. PERFORMING ORGANIZATION NAME(S) AND ADDRESS(ES)

8. PERFORMING ORGANRATION REPORT NUMBER

National Aeronautics and Space Administration

Lewis Research Center

Cleveland, Ohio 44135-3191

E-8242

9. SPONSORINGMONITORING AGENCY NAME(S) AND ADDRESS(ES)

10. SPONSORINGMONITORING AGENCY REPORT NUMBER

National Aeronautics and Space Administration

Washington, D.C. 20546-0001

NASA TM-106406

11. SUPPLEMENTARY NOTES

Prepared for the 11th Symposium on Space Nuclear Power and Propulsion Systems, sponsored by the University of New Mexico, Albuquerque, New Mexico, January 9-13, 1994. Responsible person, Jeffrey A. George, organization code 6830, (216) 433-7108.

12a. DISTRIBUTIONAVAILABILITY STATEMENT

12b. DISTRIBUTION CODE

Unclassified-Unlimited

Subject Categories 16 and 20

13. ABSTRACT (Maximum 200 words)

NASA has completed a preliminary mission and systems study of nuclear electric propulsion (NEP) systems for "split-sprint" human exploration and related robotic cargo missions to Mars. This paper describes the study, the mission architecture selected, the NEP system and technology development needs, proposed development schedules, and estimated development costs. Since current administration policy makers have delayed funding for key technology development activities that could make Mars exploration missions a reality in the near future, NASA will have time to evaluate various alternate mission options, and it appears prudent to ensure that Mars mission plans focus on astronaut and mission safety, while reducing costs to acceptable levels. The split-sprint nuclear electric propulsion system offers trip times comparable to nuclear thermal propulsion (NTP) systems, while providing mission abort opportunities that are not possible with "reference" mission architectures. Thus, NEP systems offer short transit times for the astronauts, reducing the exposure of the crew to intergalactic cosmic radiation. The high specific impulse of the NEP system, which leads to very low propellant requirements, results in significantly lower "initial mass in low earth orbit" (IMLEO). Launch vehicle packaging studies show that the NEP system can be launched, assembled, and deployed, with about one less 240 -metric-ton heavy lift launch vehicle (HLLV) per mission opportunity - a very large cost savings! Technology development cost of the nuclear reactor for an NEP system would be shared with the proposed nuclear surface power systems, since nuclear systems will be required to provide substantial electrical power on the surface of Mars. The NEP development project plan proposed includes evolutionary technology development for nuclear electric propulsion system that expands upon SP-100 (Space Power - 100 $\mathbf{k w}_{\mathrm{e}}$ ) technology that has been developed for lunar and Mars surface nuclear power, and small NEP systems for interplanetary probes. System upgrades are expected to evolve that will result in even shorter trip times, improved payload capabilities, and enhanced safety and reliability. Nonnuclear technology development for the NEP system is estimated to cost about \$721 M (1993 \$). Nuclear technology development costs are not included in the costs in this report, since these costs will be incurred in the nuclear surface power development program. NEP Phase $A / B$ studies are estimated to cost about $\$ 154 \mathrm{M}$. Flight system hardware development (Phase CID) is estimated to cost about $\$ 2.8 \mathrm{~B}$, and fabrication of flight hardware is estimated to be about $\$ 7.8 \mathrm{~B}$ for four mission opportunities in $2009,2011,2014$, and 2016 .

14. SUBJECT TERMS

Space; Nuclear; Propulsion; NEP; Electric propulsion; Exploration; Mars

\begin{tabular}{|c|c|c|}
\hline $\begin{array}{c}\text { 17. SECURTY CLASSIFICATION } \\
\text { OF REPORT } \\
\text { Unclassified }\end{array}$ & $\begin{array}{c}\text { 18. SECURITY CLASSIFICATION } \\
\text { OF THIS PAGE } \\
\text { Unclassified }\end{array}$ & $\begin{array}{c}\text { 19. SECURIY CLASSIFICATION } \\
\text { OF ABSTRACT } \\
\text { Unclassified }\end{array}$
\end{tabular}

NSN 7540-01-280-5500 